\title{
Synthetic Approaches and Biological Activities of Heterocyclic Pyrazoline
}

\section{Amana Parveen, Shashi Kiran Misra, Anupriya Kapoor, Yuthika Narayan, Shivam Kumar Verma, Pramod Chauhan and Ajay Kumar*}

School of Pharmaceutical Sciences, CSJM University, Kanpur, India

*Corresponding Author: Ajay Kumar, School of Pharmaceutical Sciences, CSJM

University, Kanpur, India.
Received: October 05, 2021

Published: October 25, 2021

(C) All rights are reserved by Ajay Kumar., et al.

\section{Abstract}

Nitrogen-containing heterocyclic combinations are widely explored in the synthesis and development of a variety of chemicals in therapeutic sciences. Pyrazolines are one of the major heterocyclic molecules that take a crucial part by the virtue of their pharmacological properties, pyrazolines are remarkable and enormousnitrogen-containing 5-membered heterocyclic combinations and various methods for their mixing have been shown. Several subordinates of pyrazoline were found to have significant normal activities, which revived the development of assessment in this area. They have a couple of prominent effects, similar to antimicrobial, antimycobacterial, antifungal, antiamoebic, alleviating, torment easing, upper and anticancer activities. 2-pyrazolines give off an impression of being the regularly pondered pyrazoline-type compounds. These combinations are by and large prepared from the cyclization of chalcones with hydrazine and its auxiliaries under alcoholic conditions. Pyrazolines are the diminished types of pyrazoles Subsequently, a tremendous number of such pyrazolines using particularly designed methods for their arranging have been portrayed in this article. The current study gives an understanding viewpoint to pyrazolines synthesis and its biological activities.

Keywords: Pyrazole; Pyrazoline; Synthesis; Biological Activities; Pharmacological Properties; Chalcone

\section{Introduction}

Drug science is committed to the revelation and improvement of new specialists for treating sicknesses. Inorganic compound keeps on being significant in treatment, for instance, as acid neutralizers, mineral enhancements, and radio-drugs, however natural atoms inside caressingly explicit pharmacological exercises are prevailing. The goal of therapeutic science is the plan and creation of mixtures that can be utilized as medication for the avoidance, treatment, and fix of people or creature diseases. It is worried about the innovation, disclosure, plan, distinguishing proof of organically dynamic mixtures, the investigation of their pharma- cokinetic and pharmacodynamic profiles, understanding of their method of activity at the sub-atomic level and the development of construction action relationship (SAR), the connection between substance structure and pharmacological movement for a progression of mixtures. The five and six-membered heterocyclic nitrogencontaining frameworks, for example, pyrazole, imidazole, triazoles, thiazolidine, pyrazolidine, and so forth, are far by the most significant in the continuous examination for more useful medications in the fields, hostile to bacterial, fungicidal, calming, anticonvulsant, diuretics, and antihistaminic, and so on [1]. Heterocyclic mixtures are pervasive and assume an essential part in drugs revelation, 
among them, pyrazole goes about as an underlying subunit of more perplexing regular items, involve a significant situation in restorative science [2].

\section{Pyrazole}

The term Pyrazole was given by Ludwig Knorr in 1883. Pyrazole (Figure 1) alludes to the class of straightforward sweet-smelling ring natural mixtures of the heterocyclic series portrayed by a 5 -membered ring structure made out of three carbon particles and two nitrogen iotas in neighboring positions. Being so formed and effect sly affecting people, they have named alkaloids, even though they are uncommon. In 1959, the principal regular pyrazole, 1-pyrazolyl-alanine, was detached from seeds of watermelons. Pyrazole subordinates have a long history of utilization in agrochemicals and the drug industry as herbicides and dynamic drugs. The new achievement COX-2 pyrazole inhibitors have also demonstrated the importance of these heterocyclic cycles in therapeutic science. An effective review of this class of heterocyclic lead has revealed that dynamic specialists in pharmacies containing pyrazole play an important role in therapeutic science [3]. The predominance of pyrazole centers in organically dynamic particles has heightened the need for effective approaches to make these heterocyclic leads.

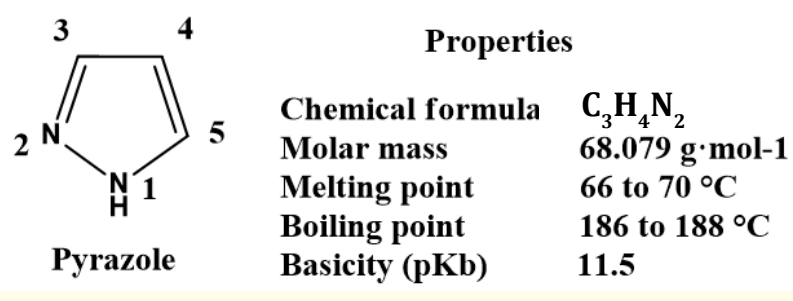

Figure 1: Pyrazole and its properties.

\section{Pyrazoline}

Pyrazoline (Figure 2) is a five-membered heterocyclic compound with two nitrogen particles close together inside the ring. It has just one intracyclic double bond and is basic. Among its various subsidiaries, 2-pyrazoline appears to be the most frequently examined pyrazoline-like compound. 2-Pyrazoline may be considered as cyclic hydrazine radical. According to the X-beam study, the con- struction of the five-membered dihydropyrazole ring was found to have envelope conformity. C-5 iota is a digression from the nearly planar arrangement of the other four molecules of the heterocycle [4]. It assumes an urgent part in the advancement of hypothesis in heterocyclic science and is likewise broadly utilized as valuable synthons in the natural blend.

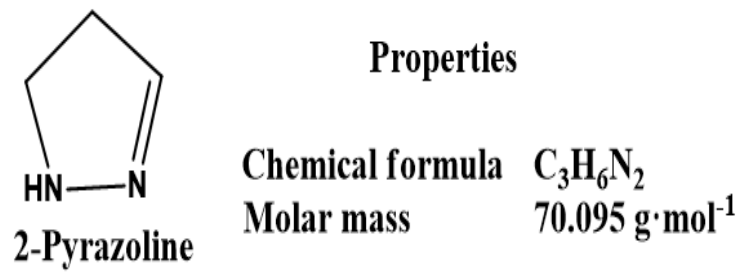

Figure 2: 2-Pyrazoline.

\section{Chemistry of pyrazoline}

Pyrazolines are hugely important nitrogen-containing heterocyclic mixtures that happen in a variety of substance and natural specialists and work on their exercises. $\mathrm{N}-\mathrm{N}$ obligation of the pyrazoline ring is controlled to be the significant reason in their organic exercises. Pyrazoline can be characterized as a dihydropyrazole having only one endocyclic double bond [5]. Depending on the double bond situation, three types of pyrazoline are possible: (a) 1pyrazoline (b) 2pyrazoline and (c) 1, 3pyrazolines, 2-pyrazoline is generally appealing and significant among all kinds of pyrazolines for continuous examinations.

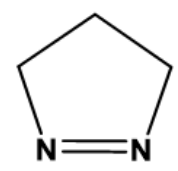

1-Pyarazoline

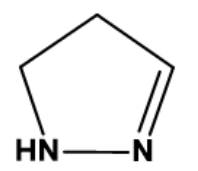

2-Pyrazoline

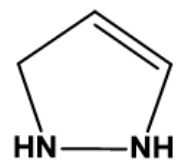

3-Pyrazoline
Figure 3: Pyrazoline Derivatives.

In reality, pyrazolines are the diminished types of pyrazoles, while pyrazolidine is a decreased type of pyrazole. 


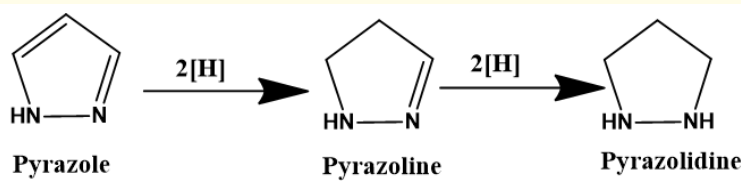

Figure 4: Hydrogenation of pyrazole to pyrazoline then pyrazolidine.

Pyrazoline subordinates have been found in normal items as nutrients, alkaloids, and shades. Subsidiaries of pyrazolines have assumed a significant part throughout the entire existence of heterocyclic science and have been utilized as significant pharmacophores and synthons in the field of natural science in drug designing [6]. It was found that the branches of pyrazoline were waiting for antimicrobial, calming, analgesic, antipyretic, energizing,antituberculosis,anti-amoebic,deworming,anti-convulsant, antihypertensive, anti-diabetic, anti-tumor, anti-HIV, quasi-sedative, cell reinforcement, insecticidal, sedating, and receptor-specific organic movement [7].

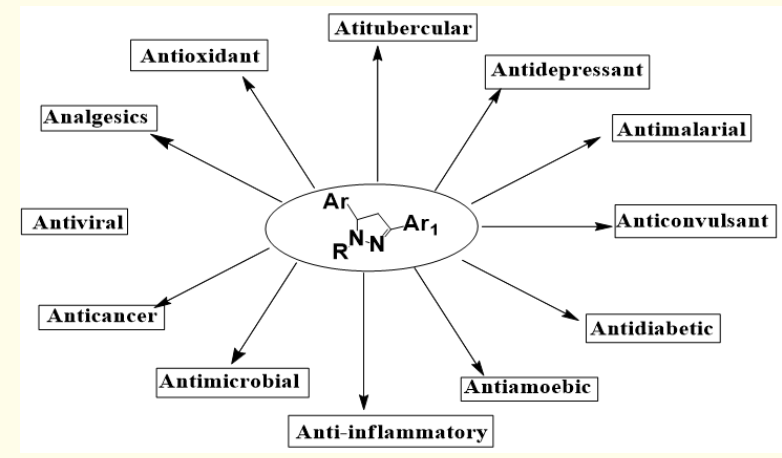

Figure 5: Pyrazoline Derivatives indicate a wide variety of biological effects.

Synthesis of pyrazoline derivatives

Writing review uncovers a few manufactured conventions for the union of these mixtures and the presence of this center in any atom assumes a critical part in improving the action. Phenyl rings containing halogen and methoxy bunches have shown critical organic exercises or improve the natural exercises of heterocyclic subsidiaries drastically. A particularly well-known technique (Figure 6) is based on the response of $\alpha, \beta$-unsaturated aldehydes, and ketones with hydrazines. Such a fabulous history provoked us to survey the union of pyrazolines as an earnest need that can have natural and restorative significance [8].

In the $19^{\text {th }}$ century, Fischer and Knoevenagel orchestrated and represented 2pyrazolines, by a basic reflux response of aldehydes and ketones, $\beta$-unsaturated with phenylhydrazine in corrosive acid. There is an assortment of techniques for fusing branches of pyrazoline [9].

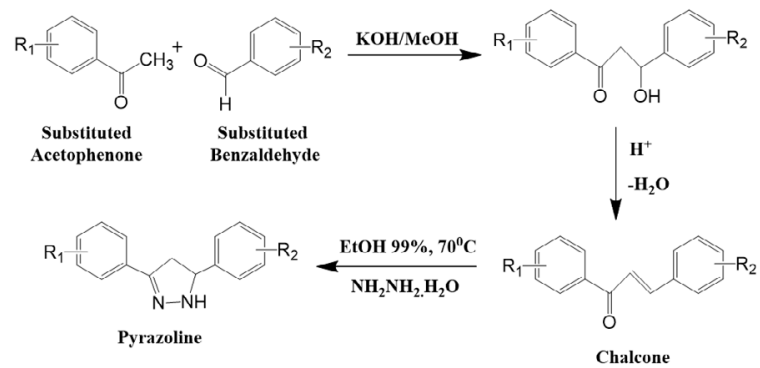

$$
\begin{aligned}
& \text { a: } \mathrm{R}_{1}=2^{\prime}-\mathrm{OH}, 4^{\prime}-\mathrm{OCH}_{3} ; \mathbf{R}_{2}=3-\mathrm{OCH}_{3}, 4-\mathrm{OCH}_{3} \\
& \text { b: } \mathrm{R}_{1}=\mathbf{4}^{\prime}-\mathrm{NO}_{2} ; \mathrm{R}_{2}=4-\mathrm{N}_{2}\left(\mathrm{CH}_{3}\right)_{2} \\
& \text { c: } \mathrm{R}_{1}=2^{\prime}-\mathrm{OH} ; \mathrm{R}_{2}=2-\mathrm{OCH}_{3}, 4-\mathrm{OCH}_{3}
\end{aligned}
$$

Figure 6: Scheme for Pyrazoline Derivative.

\section{Methods of preparation of pyrazolines}

The pyrazoline derivatives demonstrate vivid pharmacological activities like antiviral, antibacterial, antitubercular etc. there are several approaches that are utilized for the synthesis of the derivatives of pyrazoline, few of which are explored here.

Under microwave illumination, an easy and prolific cyclo condensation in a soluble watery media produces a one-pot blend of nitrogen-containing heterocycles from alkyl dihalides and essential amines and hydrazines (Figure 7) [10].

Unique accumulations of ketones, aldehydes, and hydrazine monohydrochloride readily shaped pyrazoline intermediates under delicate conditions. In situ oxidation using bromine has managed to manage the cost of a large assortment of pyrazoles with 


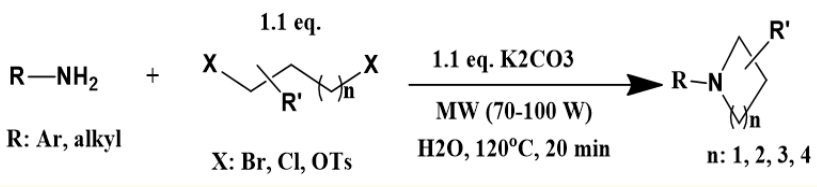

Figure 7: Synthesis of Pyrazoline derivatives via Condensation reaction.

excellent yields. 3,4,5 tri-substituted pyrazoles by simple heating of the pyrazolines in DMSO under oxygen (Figure 8) [11].<smiles>[R]CC([R])=O</smiles>

R: Ar 1 alkyl R": Ar 1 alkyl

Figure 8: Synthesis of Pyrazoline derivatives via In situ oxidation.

Arylhydrazines Regio selectively respond with 3-butynol within the sight of a synergist measure of zinc triflate to give aryl-subbed pyrazolines (Figure 9). The subsequent items are effectively oxidized in a one-pot technique to the relating pyrazoles [12].

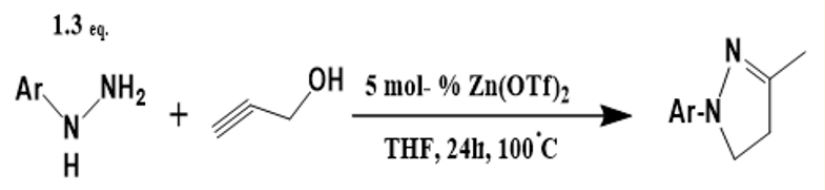

Figure 9: Synthesis of Pyrazoline derivatives via Oxidation reaction.

Using an effective and concurrent development of C(sp3)- $\mathrm{N}$ and $\mathrm{C}(\mathrm{sp} 3)-\mathrm{C}(\mathrm{sp} 2)$ securities under moderate circumstances, a palladium-catalyzed aminoarylation of unactivated alkenes in,-unsaturated hydrazones generates variably subbed dihydropyrazoles (Figure 10) in high yields [13].

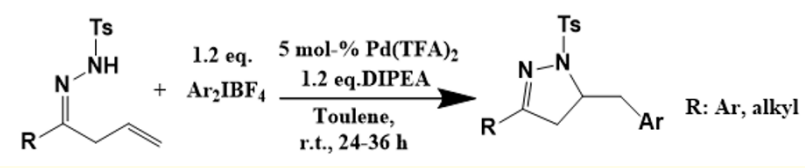

Figure 10: Synthesis of Pyrazoline derivatives via aminoarylation of unactivated alkenes.

From the 2-alkyn-1-ones comparator, various 1-acyl-5-hydroxy-4,5-dihydro1- $H$-pyrazoles were constructed in good yields (Figure 11). The accompanying dihydropyrazoles are dried and iodinated at room temperature using IC 1 and $\mathrm{Li}_{2} \mathrm{CO}_{3}$, yielding 1-acyl4-iodo-1-H-pirazoles [14].

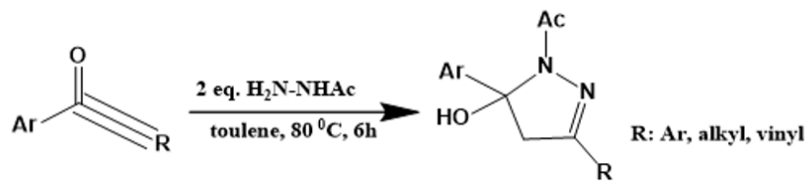

Figure 11: Synthesis of Pyrazoline derivatives via Iodination method.

In situ framed 1,2-diaza-1,3-dienes were utilized in formal [4 +1 ]-annulation responses with fluorinated sulfur ylides to give 5-(trifluoromethyl) pyrazolines (Figure 12) in great yields [15].

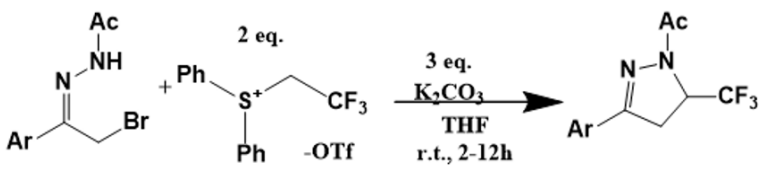

Figure 12: Synthesis of Pyrazoline derivatives via $[4+1]$-annulation reaction. 
A novel, productive, and general domino response of 2-acylaziridines with the Huisgen zwitterions outfits 2-pyrazolines (Figure 13). A potential system for the domino succession is proposed [16].

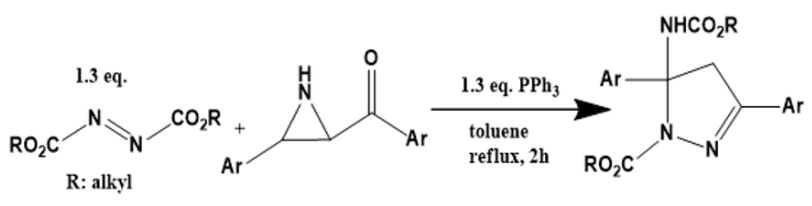

Figure 13: Synthesis of Pyrazoline derivatives via Huisgen reaction.

An advantageous copper-catalyzed intra-/intermolecular diamination of $\beta, \gamma$-unsaturated hydrazones with straightforward amines empowers an effective admittance to different nitrogencontaining pyrazolines (Figure 14) under gentle response conditions [17].

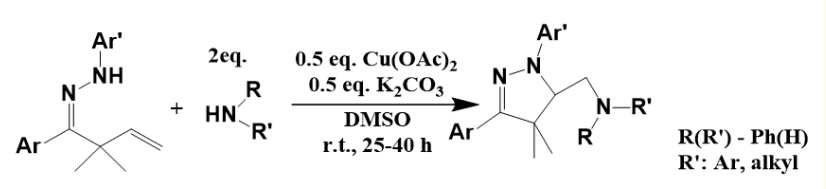

Figure 14: Synthesis of Pyrazoline derivatives via Diamination reaction.

Various biological activities of pyrazoline derivatives

\section{Antimicrobial activity}

Extensive work describing the antimicrobial profile of pyrazoline has been completed. Improvement in protection by antimicrobial specialists against important bacterial microbes is occurring rapidly, so new antimicrobial specialists must be sought. announced an efficient technique for the regioselective junction of new branches of thiazolylpyrazoline (1a) and analyzed the antibacterial movement of selected elements [18]. Patel., et al. developed another series of pyrazolidine-based thiazolidin4one branches (1b) and found that among recently orchestrated compounds with type 4 binding, chlorophenyl showed great action against bacterial strains [19]. A new series of 4-(4-chlorophenyl)-3-chloro-1-\{45(substituted-phenyl) 1-phenyl-4,5-dihydropyrazol-3-yl]-phenyl\}azetidin-2-one (1c) has been incorporated by ShahSH., et al. were screened for antibacterial and antifungal strains [20].
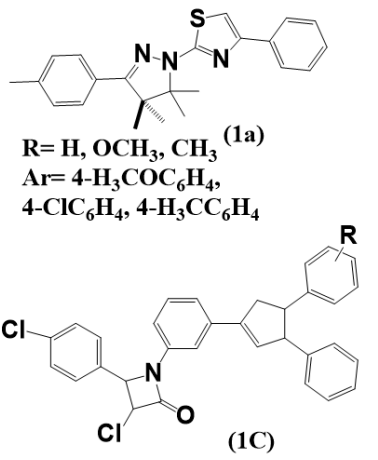

$\mathrm{R}=2-\mathrm{Cl}, 2-\mathrm{OH}, 3-\mathrm{OCH}_{3},-\mathrm{NO}_{2}$,
4-Cl, 3-OCH$, 4-\mathrm{OH}, 4-$ 4-Cl, 3- $-\mathrm{OCH}_{3}, 4-\mathrm{OH}, 4$

Figure 15: Compounds with Antimicrobial Activity.

\section{Anti-inflammatory and analgesic agents}

Enormous activities of anti-allergic and anti-inflammatory has been studied by various drug delivery systems [21-22]. Heterocyclic compounds have been explored for the study of pain-relieving effectsines. Awati SS., et al. found that the adjusted pyrazoline derivatives (2a) showed surprising calming action [23]. Neethu NJ., et al. showed the attenuating action of combined vanillin pyrazolineanalogs by measuring cyclooxygenase. The combined mixtures (2b) have shown a critical calming effect [24]. The subordinates of pyrazoline (2c) by Sridhar S., et al. have been shown to have an intriguing profile of pain relief activity [25].

\section{Antidepressant activity}

Misery is one of the problems of the focal sensory system. Pyrazolines have energizing potential. Mathew B., et al. integrated thiophene containing pyrazoline carbothioamides (3a) with promising stimulant activity. It was established that by broadening the swim- 

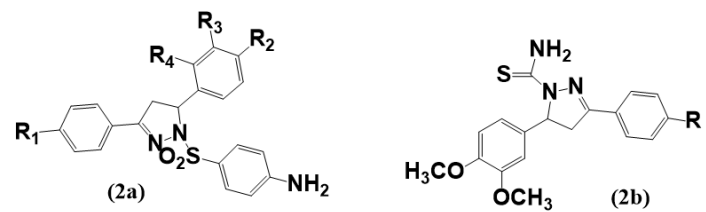

$\mathrm{R}_{1}=\mathrm{Cl}, \mathrm{OCH}_{3}$ $\mathbf{R}_{2}=\mathrm{OCH}_{3}, \mathrm{CH}_{3}, \mathrm{Cl}, \mathrm{OH}$ $\mathbf{R}_{3}=\mathbf{H}, \mathrm{Cl}$ $\mathbf{R}_{4}=\mathbf{H}, \mathrm{OCH}_{3}$ $\mathrm{R}=\mathrm{CH}_{3}, \mathrm{NH}_{2}, \mathrm{H}, \mathrm{OCH}_{3}, \mathrm{NO}_{2}$

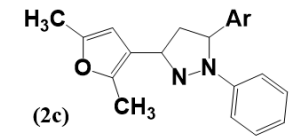

Ar = 4"'-methoxyphenyl, 3"4'-dimethoxyphenyl, 4"-fluorophenyl, 4"'-nitrophenyl, 2"-thienyl, 3",4",5"-trimethoxyphenyl, 4"-chlorophenyl, 2','4"-dichlorophenyl, 4"-methylphenyl, 9"-anthryl

Figure 16: Compounds with Anti-Inflammatory and Analgesic Activity.

ming behavior, they exhibited a common lowering in fixed status in the restrictive swim test [26]. The energizer action of a progression of 2-pyrazoline subordinates ( $3 \mathrm{~b}$ ) was studied by Kaymakcioglu BK., et al that suggested promising stimulant activity [27]. Rao AS., et al. inserted some new 1,3,5-trisubstituted-2-pyrazolines (3c) but instead evaluated their disruptive properties. Compound $3 \mathrm{a}$, like tranylcypromine, showed apical movement. The occurrence of an electron delivering bunch on the phenyl crystalline lattice bonded at the $\mathrm{C}-5$ region of 2 -pyrazoline was proven to somehow be vital for their functionality [28].

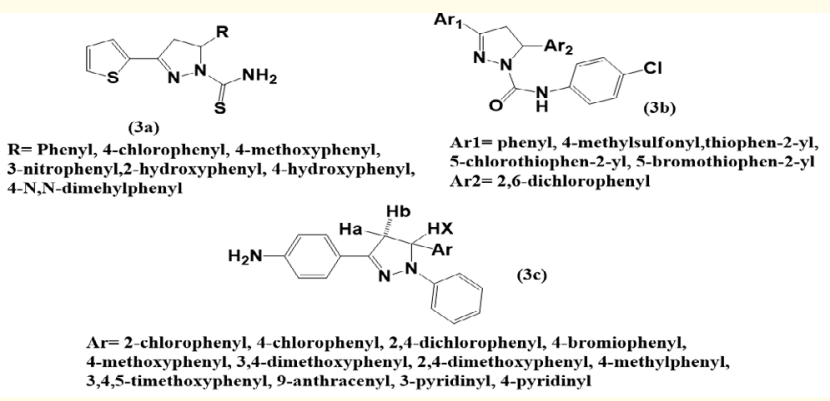

Figure 17: Compounds with Antidepressant Activity.
Antiamoebic activity

Hayat F., et al. would also include pyrazolone subordinates (4a) as well as investigated products in vitro for the antiamoebic movement against the HM1: IMSS strain of E. Histolytica [29]. Abid M., et al. combined a progression of new 1-N-subbed cyclized pyrazoline analogs of thiosemicarbazones by cyclisation of Mannich bases with thiosemicarbazide and were hence assessed for their antiamoebic action by microdilution strategy against HM1:1MSS strain of Entamoebahistolytica. Additionally, compound (4b) showed the most encouraging antiamoebic activity [30]. Antiamoebic potential of something like the compound was promising. Novel tetrazole installed 1,3,5-trisubstituted pyrazoline subordinates (4c) as Entamoebahistolytica development inhibitors were identified by Wani MY., et al. [31].

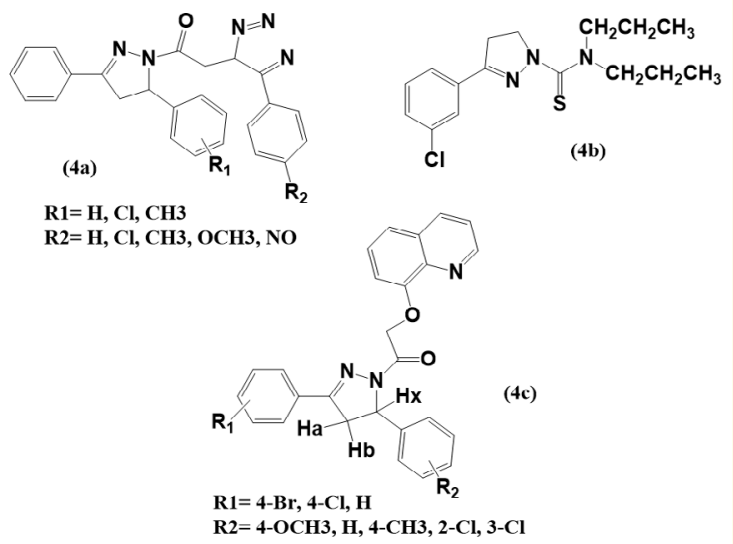

Figure 18: Compounds with Antiamoebic Activity.

\section{Anticancer activity}

Study of anticancer activity is the most concerning domain in pharmaceutical research as most of the newer outcomes are revealing day by day that address newer heterocyclic molecules $[32,33]$. Different scientists have planned pyrazolines to look at their impact on malignancy. Zhu SL., et al. explored the in vitro cytotoxic activity of isosteviol subsidiary containing pyrazoline heterocyclic components (5a) against four human cancer cell lines. It was discovered that pyrazoline heterocyclic sections that had been exposed to isosteviol were more effective in cytotoxicity [34]. Raghav N., et al. arranged cyclized subsidiary, pyrazolines (5b), and tested 
them as disease therapies for inhibitors of mammalian cathepsin $\mathrm{B}$ and cathepsin $\mathrm{H}$ [35]. Lee M., et al. used an in vitro 72-hour persistent openness MT to determine the cytotoxicity of methylpyrazoline analogs (5c) of combretastatin A-4 against the growth of disease cells in culture [36].

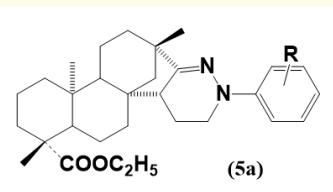

$\mathbf{R}=\mathbf{H}, \mathbf{o}-\mathbf{F}, \mathbf{m}-\mathbf{F}, \mathbf{p}-\mathbf{F}$

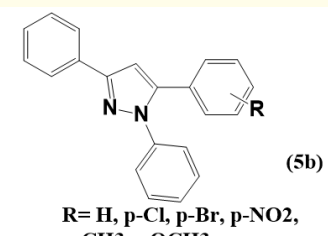
$\mathrm{p}-\mathrm{CH} 3, \mathrm{p}-\mathrm{OCH} 3$<smiles>[R4]c1cc(C2C(C)=NN(C(C)(F)F)C2c2cc([R4])c(OC)c([R])c2[R])cc(OC)c1OC</smiles>

$\mathrm{R} 1=\mathrm{H}, \mathrm{OCH} 3$

R2 $=\mathrm{H}, \mathrm{NO} 2, \mathrm{Cl}, \mathrm{OCH} 3, \mathrm{OH}, \mathrm{NO} 2$ $\mathrm{R3}=\mathrm{H}, \mathrm{CH} 3, \mathrm{Cl}, \mathrm{Br}, \mathrm{NO} 2, \mathrm{OCH} 3$ R4 $=$ H, OCH3 R5 $=\mathbf{H}$

Figure 19: Compounds with Anticancer Activity.

\section{Antiviral activity}

The occurrence of viral contaminations has been continually arising and reappearing on a worldwide scale. Compelling antiviral medications have been grown considerably more leisurely than different sorts of hostile to infective chemotherapy. One of the significant constraints has been the shortfall of explicit viral 'targets', since have cell pathways are utilized prevalently for viral replication. Pyrazoline variants have demonstrated surprising antiviral potential, including Ramajayam R., et al. indicating the viability of dual pyrazolines (6a) as a SARS virus protease inhibitor [37]. Thiazolidinonepyrazoline cross breeds (6b) were orchestrated by Havrylyuk D., et al. also, the antiviral action of blended not settled. The mixtures showed irrelevant exercises against the four strains of the flu virus [38]. Pyrazoline subsidiaries got from phenoxyacetic corrosive were accounted for by Shaharyar M., et al. also, tried for their in vitro cytotoxicity and antiviral action. The most cytotoxic of the series was 2-[4-[3-(2,4-dihydroxyphenyl)- 1-(2-hydroxybenzoyl-4,5-dihydro-1H-5-pyrazolyl]-2-methoxy phenoxy] (6c) acidic corrosive with a base cytotoxic convergence of $0.16 \mu \mathrm{g} / \mathrm{mL}$ in human undeveloped lung (HEL) cells [39].

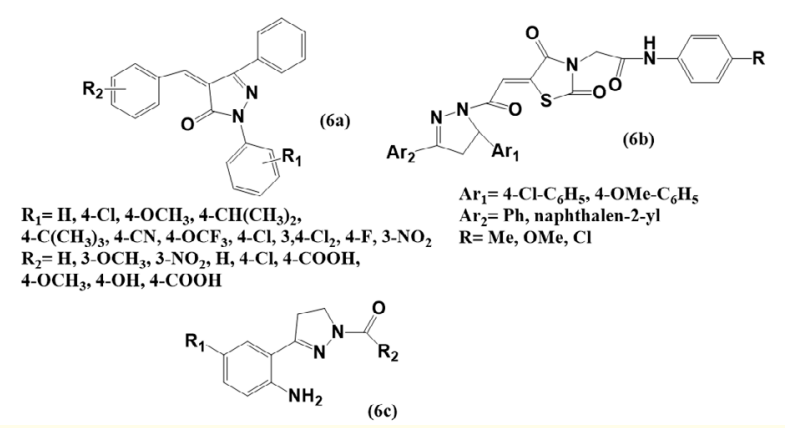

Figure 20: Compounds with Antiviral Activity.

\section{Antitubercular activity}

Tuberculosis is caused by Mycobacterium Tuberculosis contamination. Pyrazolines have been studied extensively for their antitubercular properties. Hipparagi SM and Bhanushali MD., et al. blended a series of 2-pyrazoline compounds (7a) and tested them for antitubercular activity against isoniazid-resistant Mycobacterium tuberculosis using the Microplate Alamar Blue examination method. None of the compounds were found to be comparable to conventional isoniazid [40]. Hariraj N., et al. combined and evaluated 6-bromo Coumarins (7b) pyrazolin-5-one subsidiaries as antitubercular specialists. Against M tuberculosis, all of the blended Pyrazoline-5-one subsidiaries showed potential Hostile to TB activity [41]. Taj T., et al. compared the antitubercular activity of new pyrazolinederivatizedcarbazoles (7c) to that of traditional streptomycin and pyrazinamide [42].

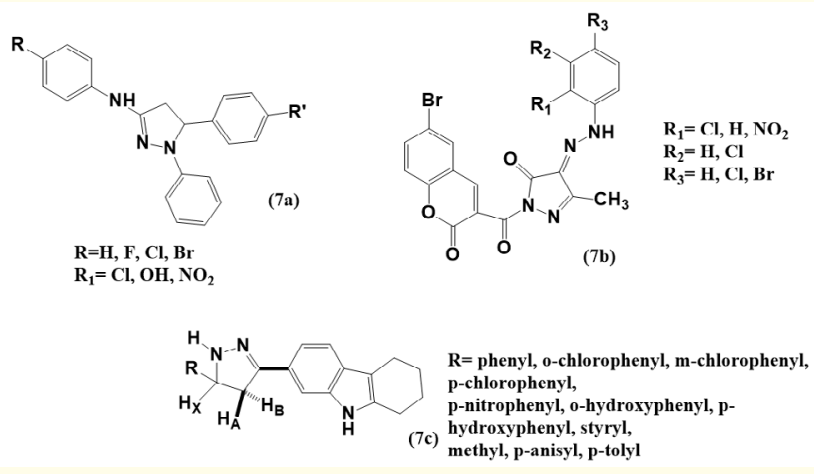

Figure 21: Compounds with Antitubercular Activity. 


\section{Antioxidant activity}

Cancer prevention agents are substances that might shield cells from the harm brought about by shaky particles known as free extremists. Kumar A., et al. 4-bromo-3(substituted phenyl)- 5(substituted phenyl)- 1-phenyl-2-pyrazoline were evaluated against oxidant and mitigating movement. The cancer prevention agent movement of compound (8a) was observed to be the strongest [43]. Venkatesh P., et al. also generated a series of Coumarin is interwoven pyrazoline-5-one subsidiaries $(8 b)$ that were investigated for cell reinforcement movement using DPPH and Nitric oxide techniques. In both ways, Compound 2 has a strong anti-cancer effect [44]. Kumar A., et al. orchestrated 3,5-disubstituted-2-pyrazolines (8c)and were evaluated for cell reinforcement movement utilizing DPPH extremist searching technique, NO rummaging test, superoxide revolutionary rummaging test, and hydrogen peroxide extremist rummaging measure. Every one of the mixtures showed great free revolutionary searching movement which is practically identical to that of the standard ascorbic acid [45].

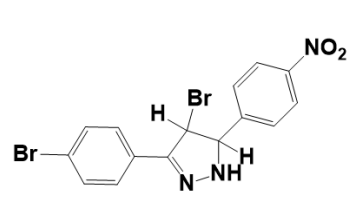

(8a)

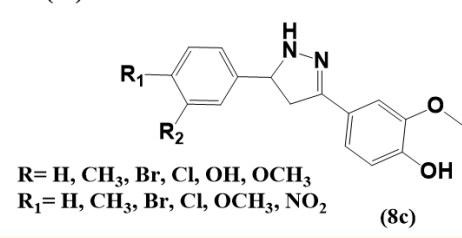

Figure 22: Compounds with Antioxidant Activity.

\section{Anticonvulsant activity}

The maximal electroshock seizure (MES) method was used to test the anticonvulsant activity of 84 integrated 3,5-diphenyl2-pyrazoline-1-carboxamide derivatives (9a) [46]. Beyhan N., et al. synthesized a series of 2-pyrazoline derivatives (9b) and tested them for anticonvulsant activity. In the PTZ test, 2-pyrazoline carboxamide subsidiaries carrying 5-bromothiophen, 5-chlorothiophen, and 2,6-dichlorophenyl bunches were found to have a critical movement among the tested mixes [47]. Rao BM., et al. integrated new 2-pyrazoline subsidiaries (9c) and assessed them for antiepileptic action. The mixtures showed great antiepileptic movement when contrasted with standards [48].

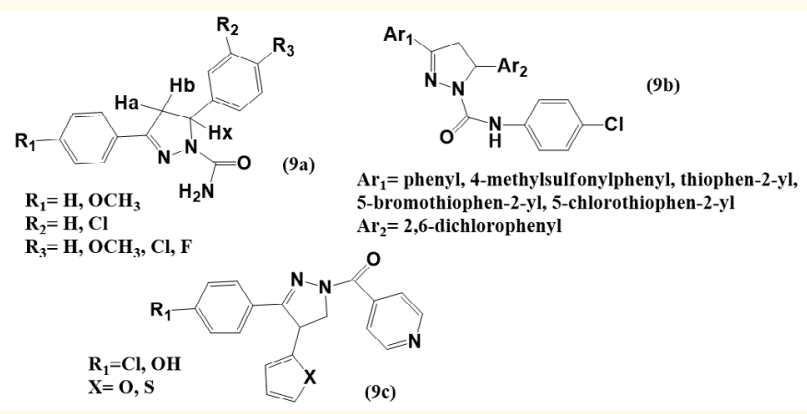

Figure 23: Compounds with Anticonvulsant Activity.

Antidiabetic activity

New pyrazoline substituted benzenesulfonylurea/thiourea subordinates were blended by Ovais S., et al. (10a) At a concentration of $0.05 \mathrm{mM} / \mathrm{kg}$ b.w., compounds with moderate to strong anti-hyperglycemic activity in glucose took care of hyperglycaemic typical rats [49]. Santhi N., et al. mixed 1,3,5-triaryl-2-pyrazolines (10b) and tested their antidiabetic activity, finding that they were more effective than hypoglycemic specialists and conventional insulin in lowering blood glucose levels [50].

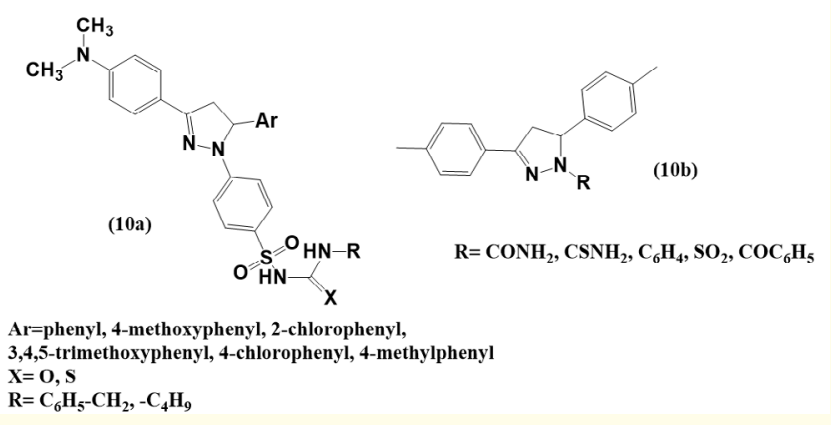

Figure 24: Compounds with Antidiabetic Activity. 


\section{Conclusion}

In this article, various approaches for the synthesis of pyrazoline are discussed with their pharmacological activities i.e. antimicrobial, antimycobacterial, antimalarial, anticonvulsant, anticancer effects etc. The pyrazoline derivatives elicited interesting arena for the researches to design newer molecules with promising therapeutic benefits that could be explored in pharmaceutical applications. Pyrazoline is a fascinating heterocyclic complex and is frequently being utilized for the synthesis of novel pyrazoline derivatives.

\section{Author's Contribution}

$\mathrm{AP}$ and AK surveyed the literature. AP drafted the article. SKM and APK and YN were involved in critical evaluation and formatting of the content. All authors have agreed to be accountable for all aspects of the work.

\section{Bibliography}

1. Shajidul K., et al. "Pyrazoline Heterocyclic: A Review". International Journal of Pharmaceutical Science and Research 12.5 (2021): 2570-2588.

2. Donald JA., et al. "Burger's Medicinal Chemistry and Drug Discovery". 6th edition, John Wiley and Sons, New Jersey (2007): 539-543.

3. Olczak-Kowalczyk D., et al. "Bacteria and Candida yeasts in inflammations of the oral mucosa in children with secondary immunodeficiency". Journal of Oral Pathology and Medicine 41.7 (2012): 568-576.

4. Ahasan NB., et al. "Cytotoxicity study of pyrazole derivatives". Bangladesh Journal of Pharmacology 2.2 (2007): 81-87.

5. Abunada NM., et al. "Synthesis and biological activity of some new pyrazoline and pyrrolo [3, 4-c] pyrazole-4, 6-dione derivatives: reaction of nitrilimines with some dipolarophiles". Molecules 13.4 (2008): 1011-1024.

6. Ziani N., et al. "Synthesis of pyrazoline derivatives from the 1, 3-dipolar cycloadditions using $\alpha, \beta$-unsaturated cyclohexanone derivatives". European Journal of Chemistry 4.2 (2013): 176-179.
7. Mahdi MF., et al. "Synthesis, characterization and preliminary pharmacological evaluation of new non-steroidal anti-inflammatory pyrazoline derivatives". European Journal of Chemistry 6.4 (2015): 461-467.

8. Sharma TC., et al. "Synthesis of some isomeric pyrazoles". Chemischer Informations Dienst 14.36 (1983).

9. Varghese B., et al. "Unveiling a versatile heterocycle: pyrazoline-a review". RSC Advances 7.74 (2017): 46999-47016.

10. Ju Y., et al. "Aqueous N-heterocyclization of primary amines and hydrazines with dihalides: microwave-assisted syntheses of N-azacycloalkanes, isoindole, pyrazole, pyrazolidine, and phthalazine derivatives". The Journal of organic chemistry 71.1 (2006): 135-141.

11. Lellek V., et al. "An Efficient Synthesis of Substituted Pyrazoles from One-Pot Reaction of Ketones, Aldehydes, and Hydrazine Monohydrochloride". Synlett 29.8 (2018): 1071-1075.

12. Alex K., et al. "Zinc-catalyzed synthesis of pyrazolines and pyrazoles via hydrohydrazination". Organic Letters 10.12 (2008): 2377-2379.

13. Yang MN., et al. "Synthesis of dihydropyrazoles via ligandfree Pd-catalyzed alkene aminoarylation of unsaturated hydrazones with diaryliodonium salts". Organic Letters 19.19 (2017): 5208-5211.

14. Cho CH., et al. "Solution-phase parallel synthesis of a multisubstituted benzo [b] thiophene library". Journal of Combinatorial Chemistry 11.5 (2009): 900-906.

15. Wang Z., et al. "Synthesis of 5- (trifluoromethyl) pyrazolines by formal $[4+1]$-annulation of fluorinated sulfur ylides and azoalkenes". Organic letters 20.4 (2018): 934-937.

16. Cui SL., et al. "Facile access to pyrazolines via domino reaction of the Huisgen zwitterions with aziridines". Organic Letters 10.1 (2008): 13-16.

17. Chen M., et al. "Copper-catalyzed diamination of alkenes of unsaturated ketohydrazones with amines". Organic Letters 20.3 (2018): 510-513. 
18. Sharifzadeh B., et al. "Facile regioselective synthesis of novel bioactive thiazolyl-pyrazoline derivatives via a three-component reaction and their antimicrobial activity". Bioorganic and Medicinal Chemistry Letters 23.2 (2013): 548-551.

19. Patel PI., et al. "Design, synthesis and pharmacological evaluation of new series of pyrazolines based thiazolidin-4-one derivatives". Chemical Science Transactions 2.4 (2013): 1089-93.

20. Shah SH., et al. "Synthesis and Bio-Evaluation of Some New Phenyl Pyrazoline Derivatives from Pera-ChloroBenzaldehyde Moiety". Journal of Chemistry and Chemical Sciences 4.1 (2014): 1-7.

21. Misra SK., et al. "Passage delaying microbeads for controlled delivery of loratadine". PDA Journal of Pharmaceutical Science and Technology 62.6 (2008): 421-428.

22. Kapoor A., et al. "Acitretin loaded nanocarrier gel: formulation and exploration of in - vitro release kinetics". Current Nanomedicine 11 (2021): 1-10.

23. Gonjare NS., et al. "Synthesis and anti-inflammatory activity of some novel 1, 2-pyrazoline derivatives". Der Pharma Chemica 5.3 (2013): 86-91.

24. Neethu NJ., et al. "Synthesis, Biological evaluation and Evaluation of Pyrazoline Analogues of Vanillin". International Journal of Pharmaceutical Sciences and Drug Research 6.2 (2014): 128131.

25. Sridhar S., et al. "Synthesis and analgesic studies of some new 2-pyrazolines". E-Journal of Chemistry 9.4 (2012): 1810-1815.

26. Mathew B., et al. "Synthesis, preclinical evaluation and antidepressant activity of 5-substituted phenyl-3- (thiophen-2-yl)-4, 5-dihydro-1H-pyrazole-1-carbothioamides". EXCLI Journal 13 (2014): 437.

27. Kaymakcioglu BK., et al. "Antidepressant-like activity of 2-pyrazoline derivatives". Clinical and Experimental Health Sciences 3.3 (2013): 154.

28. Rao AS., et al. "Anticonvulsant and Antidepressant Activity Studies of Synthesized Some New 1, 3, 5-trisubstituted-2-pyrazolines". International Journal of PharmTech Research 6.3 (2014): 1113-1123.
29. Hayat F., et al. "Synthesis, characterization, antiamoebic activity and cytotoxicity of novel series of pyrazoline derivatives bearing quinoline tail". European Journal of Medicinal Chemistry 45.10 (2010): 4669-4675.

30. Abid M., et al. "Synthesis and antiamoebic activities of 1-N-substituted cyclisedpyrazoline analogues of thiosemicarbazones". Bioorganic and Medicinal Chemistry 13.6 (2005): 2213-2220.

31. Wani MY., et al. "Synthesis and in vitro evaluation of novel tetrazole embedded 1, 3, 5-trisubstituted pyrazoline derivatives as Entamoebahistolytica growth inhibitors". European Journal of Medicinal Chemistry 54 (2012): 845-854.

32. Misra SK., et al. "Anticancer potential of indole derivatives: an update". Physical Sciences Review (2021).

33. Kapoor A. "Biologics in the management of psoriasis". Acta Scientific Pharmaceutical Science 5.10 (2021): 77-83.

34. Zhu SL., et al. "Design and stereoselective synthesis of novel isosteviol-fused pyrazolines and pyrazoles as potential anticancer agents". European Journal of Medicinal Chemistry 65 (2013): 70-82.

35. Raghav N., et al. "SAR studies of differently functionalized chalcones based hydrazones and their cyclized derivatives as inhibitors of mammalian cathepsin B and cathepsin H". Bioorganic and Medicinal Chemistry 22.15 (2014): 4233-4245.

36. Lee M., et al. "A novel class of trans-methylpyrazoline analogs of combretastatins: synthesis and in-vitro biological testing". European Journal of Medicinal Chemistry 46.7 (2011): 30993104.

37. Ramajayam R., et al. "Synthesis and evaluation of pyrazolone compounds as SARS-coronavirus 3C-like protease inhibitors". Bioorganic and Medicinal Chemistry 18.22 (2010): 7849-7854.

38. Havrylyuk D., et al. "Synthesis and biological activity evaluation of 5-pyrazoline substituted 4-thiazolidinones". European Journal of Medicinal Chemistry 66 (2013): 228-237.

39. Shaharyar M., et al. "Synthesis and evaluation of in vitro antiviral activity of novel phenoxy acetic acid derivatives". Journal of Enzyme Inhibition and Medicinal Chemistry 24.3 (2009): 876882. 
40. Hipparagi SM., et al. "Synthesis and evaluation of anti-tubercular activity of some novel 2-pyrazoline derivatives". Journal of the Scientific Society 40.2 (2013): 80.

41. Hariraj N., et al. "Synthesis of certain pyrazoline-5-one derivatives of 6-bromo coumarins and evaluation of their biological activities". Pharmacie Globale 3.12 (2012): 1.

42. Taj T., et al. "One-pot synthesis of pyrazolinederivatisedcarbazoles as antitubercular, anticancer agents, their DNA cleavage and antioxidant activities". European Journal of Medicinal Chemistry 46.9 (2011): 4366-4373.

43. Kumar A., et al. "Synthesis and biological evaluation of new 4-bromo-3, 5-diaryl-1-phenyl-2-pyrazoline derivatives as antioxidant and anti-inflammatory agents". International Journal of Research and Development in Pharmacy and Life Sciences 2.2 (2013): 349-354.

44. Venkatesh P., et al. "Synthesis of Coumarin fused Pyrazoline5-one derivatives and Screening for their antimicrobial and antioxidant activite". Journal of Pharmacy Research 5.5 (2012): 2875-7.

45. Kumar A., et al. "Synthesis and evaluation of antioxidant activity of novel 3, 5-disubstituted-2-pyrazolines". Bulletin of Faculty of Pharmacy, Cairo University 51.2 (2013): 167-173.

46. Siddiqui AA., et al. "Synthesis and anticonvulsant activity of some substituted 3, 5-diphenyl-2-pyrazoline-1-carboxamide derivatives". Chemical Science Journal, CSJ-8 (2010).

47. Beyhan N., et al. "Synthesis and anticonvulsant activity of some 2-pyrazolines derived from chalcones". Arabian Journal of Chemistry 10 (2017): S2073-S2081.

48. Rao B., et al. "Synthesis, characterization and evaluation of anti-epileptic activity of four new 2-pyrazoline derivatives compounds". Scholars Journal of Applied Medical Sciences 1.1 (2013): 20-27.

49. Ovais S., et al. "Synthesis and biological evaluation of some new pyrazoline substituted benzenesulfonylurea/thiourea derivatives as anti-hyperglycaemic agents and aldose reductase inhibitors". European Journal of Medicinal Chemistry 80 (2014): 209-217.
50. Emayavaramban, M., et al. "Synthesis, Characterization and Anti-diabetic activity of 1, 3, 5-triaryl-2-pyrazolines in acetic acid solution under Ultrasound Irradiation". International Letters of Chemistry, Physics and Astronomy 9 (2013): 172-185.

\section{Volume 5 Issue 11 November 2021 \\ (C) All rights are reserved by Ajay Kumar., et al.}

